Home | Archives | About | Login | Submissions | Notify | Contact | Search

ES Home $>$ Vol. 3, No. $2>$ Art. 1

Copyright $\odot 1999$ by The Resilience Alliance ${ }^{*}$

The following is the established format for referencing this article:

Holling, C. S. 1999. Introduction to the special feature: just complex enough for understanding; just simple enough for communication. Conservation Ecology 3(2): 1. [online] URL: http://www.consecol.org/vol3/iss2/art1/

\title{
Introduction to the Special Feature: Just Complex Enough for Understanding; Just Simple Enough for Communication
}

\author{
C.S. (Buzz) Holling
}

University of Florida

Published: September 14, 1999

Science has a bad name in too many places. And ecological science contributes to that bad reputation. Some of that loss in stature is inevitable as private economic interests conflict with robust ecological understanding. And those conflicts will grow as the scale of human impacts at both the regional and global level continues to increase. Conflicts between goals of maintaining biodiversity Vs those of private development or between policies to reduce greenhouse gas emissions Vs desires to maintain the fossil fuel industry are just the beginning.

But some of the bad reputation is deserved. As ecologists, we think we know all that we need to know when, in fact, we lack the philosophical, theoretical and empirical foundations for the issues at hand. That failure to recognize the limitations of our knowledge produces partial understanding that is just not complex enough to be useful. And even when we do know enough to converse and suggest actions, we are dreadful communicators and are ignorant of people and politics. We often lack the talent for simple communication of complex ideas. That is why even the phrase conservation ecology is viewed negatively by some of our most supportive readers and authors. In some countries like the UK and Australia, for example, the phrase implies naïve policy and trivial science.

Human transformation of regions and the planet requires an ecological science that recognizes that change is inevitable, that change can be precipitous, that uncertainty and unpredictability are inherent in any future, and that events are not isolated in the present or in one place but reverberate across scales in time and space. As ecologists, we must communicate and explore such understanding in ways that engage the public and scholars in other disciplines.

I wrote an editorial for the launch of Conservation Ecology in 1995 that tried to diagnose the kinds of science needed (Two Cultures of Ecology). I suggested that reductionist science, i.e. the science of parts, was essential to provide bricks for an edifice, but not the strategic design of the edifice. Such strategic design is needed for appropriate diagnosis and policy, and it has to emerge from a science of integration. A science of integration combines research and application, is interdisciplinary and faces the realization that knowledge of the system we deal with is always incomplete. It acknowledges that surprise is inevitable and that there will rarely be unanimity 
of agreement among peers - only an increasingly credible line of tested argument. Not only is the science incomplete, the system itself is a moving target, evolving because of the impacts of management and the progressive expansion of the scale of human influences on the planet.

The great excitement in science now, however, is that such a science of integration is actively being developed. Its development is a collaborative endeavor among several disciplines, and at the center is a focus on ecological systems, evolution, complex adaptive systems and global change. The papers in this special feature on Recent Advances in Ecological Theory and Practice highlight these new developments toward integration. The lead paper, its commentaries and the concluding paper are outstanding examples of initiatives to explore the very frontiers of theory concerning the sustainability of linked systems of people, economics, and nature. The five other articles are a fine set of essays that were among the top ones selected in a competition of the James S. McDonnell Foundation. I'll describe those essays first, and leave the description of the lead paper and concluding articles for a suspense-laden conclusion!

\section{The McDonnell Centennial Essays}

The seeds for the Feature came from a remarkable competition of the McDonnell Foundation, the James S. McDonnell Centennial Fellowship Program. The competition was designed to encourage scientists whose work will, over the first half of the 21st century, contribute substantially to the development of knowledge and its responsible application. Ten fellowships of one million dollars each were awarded -- two in each of five categories. One of those categories was entitled Global and Complex Systems, and five of the top essays in that category are presented here. As a measure of the integrative nature of the essays, they were judged by a panel that included active scientists and scholars from ecology, economics, physics, geography, atmospheric and oceanographic sciences, computer science and political science.

There were two important restrictions to the competition: applicants had to be under 40 years of age and they had to submit an essay understandable to a multi-disciplinary and public audience.

Those essays are of major importance. The goal of the competition was to encourage both top-rate science and also lucid communication of complex ideas in a way that would foster cooperation with other disciplines and the public. The essays were therefore similar in purpose to what Conservation Ecology defines as "Perspectives". These are not reviews with extensive references, but descriptions of personal research or experience where personal judgements, based on deep experience, and on the most recent advances in a field, are sought. The goal was not to summarize a field, but to communicate the excitement and substance of one person's work, its relevance to future science, methods, or, in some cases, policy.

Four of the papers are presented here, and a fifth one will appear later (Neelin, Coupled Systems in Climate Dynamics). They were among the top essays submitted in the Global and Complex Systems Panel. Any could have been a winner. They each represent glimpses into some of the best theory and practice that is now informing ecological, global and complex systems science. The two essays that were chosen: "Currents of Change: Investigating the Ocean's Role in Climate" by S. Ramsdorf and "Scales that Matter: Untangling Complexity in Ecological Systems" by M. Pascual, will be published in the spring of 2000 by Joseph Henry Press in a full set of the ten winning essays from all five categories.

The first published here is by Marten Scheffer, "Searching for explanations of nature in the mirror world of mathematics". Scheffer presents an essay that captures the fascination and beauty of both nature and of the mathematical explanations of nature - all without a single equation. The ecological science is impeccable- slow and fast dynamics, multi-stable states, minimalist simulation models, and empirical testing all leading to Lake Restoration policies that work. It reviews contributions that are as important for practice as for theory. And the test is that the policies work because the theory is appropriate and the explanations communicate to a wide audience. The essay communicates not only the substance, but also the wonderment of science and of nature.

Martin A. Nowak in "The mathematical biology of human infections" presents a clear and incisive review that captures the extraordinarily important advances that have been made in understanding the evolution, ecology, 
and immunology of human diseases. For our purposes, two features stand out. First, the emergence of new diseases is proving to be a key global change issue. An example is AIDS. Increasing evidence indicates that the disease moved from chimpanzee hosts to humans. That probably occurred many times in the past, with no lasting consequence. But land use transformations and disruptions in human societies led to evolution of the disease's virulence, and movements of people led to its global spread. Other poorly known diseases, waiting in parts of the world that are being degraded ecologically and destabilized socially, have the same potential. Second, the big advances in understanding came from an interaction between modeling and empirical studies at scales ranging from the ecosystem-like dynamics of the immune system, to evolutionary dynamics occurring at regional and global scales.

Timothy Lynam, in "Adaptive analysis of locally complex systems in a globally complex world", boldly links analyses and models of the social, economic, and ecological past, present, and future in the Zambezi Valley of Africa. It is a remarkable example of wedding existing theory with novel methods of data collection, involving both traditional science and the knowledge of local people. It is equally an example of thoroughly sensible and parsimonious modeling that cuts through the complexity to a minimal set of critical relations at the appropriate scales. He places this work in the historical and policy setting of the region, where remarkable experiments are underway that hold the promise to transform crises into sustainable opportunity for humans and ecosystems. In one of these experiments he remarks that "for decades local residents had been perceived and treated as little more than environmental pillagers. Suddenly their status was elevated to that of caring and responsible natural resource managers". It is the lessons of these kinds of discoveries in one region of the world that need to be transferred and adapted to other regions.

Gretchen C. Daily in "Developing a Scientific Basis for Managing Earth's Life Support Systems" directly addresses the issue raised at the beginning of this introduction. That is, the scientific enterprise is losing support at a time when a sound scientific basis is a critical prerequisite for solving the environmental issues society now faces. Human transformations of the biosphere are unprecedented in scale, and are occurring at rates and in directions that are not sustainable, posing serious threats to human well being. She presents a general conceptual framework - the Ecosystem Services Framework - that gives focus for both research and application in this complex area. From that comes a metric of ecosystem change that requires development of measurements of the capacity of human-dominated lands to support biodiversity. And, finally, she summarizes the needs for a revolution in attitude that fosters communication and interaction between scientific and business and policy communities. To an impressive degree, she is creating the most effective steps in that effort, and in the process she is advancing a science that integrates ecology, economics and social science.

\section{The Concluding and Lead Articles}

The remaining two papers and the related commentaries, cover very new territory linking economics, ecology, and the social sciences. The concluding paper (Janssen, M. A. and S. R. Carpenter. Managing the Resilience of Lakes: a Multi-Agent Modeling Approach) has an important place here, because it presents a unique integration of two new areas of theory - from cultural theory and ecosystem theory. It's focus is the development of an integrated model for lake management in which agents (resource managers) respond to unexpected changes in the state of the lake. The authors' goal is to use caricatures of social decision making and explore consequences when alternative expectations of managers confront surprises produced by their own management. The models and analysis are not meant to give answers, but to provoke relevant questions. In harmony with that intent, a demonstration version of the model can be downloaded from an appendix, for readers own exploration.

I have kept the description of the lead paper for the end of this introduction, because of its importance and because it leads to a specific invitation to readers to participate in an experiment in learning.

The lead paper in this Special Feature (Stephen R. Carpenter, William Brock, and Paul Hanson. Ecological and Social Dynamics in Simple Models of Ecosystem Management) was not, in fact, part of the McDonnell competition. It could not have been because the authors were "too long in the tooth"- over 40! Nonetheless, the paper meets and exceeds the requirement set by the competition organizers for lucid communication of top-rate, integrative science. 
The Carpenter, Brock and Hanson paper has two key attributes. First, the paper presents the first set of models anywhere which integrates an appropriate level of ecosystem reality with economic optimization and decision processes. Second, the paper fully exploits a feature only possible in an electronic journal - that is the capacity for readers to download a model so as to explore its properties and usefulness in any way they chose. The models represent the actions of key actors, either as simulated by the model or, alternatively, through explicit interventions made by an individual or group who take control of any one or more of the actors' decisions. In this latter form, it becomes a learning game, where the limits and opportunities of those key actors are discovered: stakeholders, scientific or economic advisors, managers, or decision-makers. As readers explore these opportunities, another feature of Conservation Ecology, the Response facility, can be used to communicate their discoveries in order to build a community of shared understanding. In the last section of this introduction, I will describe a bit more about the models and their use in an invitation to readers to be part of a "virtual" experiment in research enquiry.

To highlight the novelty, outstanding nature, and importance of the Carpenter, Brock and Hanson paper and to seed the discussion around the issues that it raises, four Commentaries were solicited and appear immediately after the paper. Each is written from a different perspective and body of experience: that of a mathematical ecologist (Simon Levin), of a resource and ecosystem ecologist (Lance Gunderson), of political scientists (Lowell Pritchard and Steve Sanderson) and of an economist (Charles Perrings).

\section{Where to Go From Here- a Proposal to Readers}

The lead paper by Carpenter, Brock and Hanson represents the results of very deep cooperation between two wellknown scholars - one an ecosystem ecologist (Carpenter) and one an economist (Brock). The paper presents the first credible and useful set of models that makes transparent the importance of the integration of ecology, economics and social science.

Notably, the ecological and economic components of the models produce radically different results if operated separately than when operated together. As a result, policies and actions suggested by using the models are pathological if they are limited only to the best of existing arguments or assumptions of ecology or of economics alone. The models presented by Carpenter et al. are variously known as "adaptive agent", "exploratory", or "backloop" models. Their approach grew from an effort to devise the minimal set of elements capable of representing integrated natural-social systems. This minimal set appears to be: (1) a society of diverse actors, each making independent decisions about a world they co-create; (2) an ecosystem of at least three components, operating at three different speeds, linked by nonlinear interactions; (3) mechanisms for assessment, forecasting and collective action.

The suite of models is structured to facilitate understanding. Their goal is not to produce definitive solutions. They are therefore devices to aid in discoveries that deepen understanding. The models and their use also provide opportunity for opening fruitful conversations between ecologists and economists, rather than the superficial or hostile interchanges that are so common.

The more familiar models of environmental science are very different and are more appropriate during more predictable periods of incremental change. Such models are used to design engineering structures, estimate stock sizes and uncertainties, predict maximum sustainable yields, calculate optimal policies and so forth. A very different approach to modeling is needed during phases of crisis and renewal, during periods of the "back-loop" of adaptive change. Transformations in ecosystems, economies or society generate both crisis and opportunity. The priority, under such circumstances, is to understand the limits of resilience and the possibilities of social flexibility. Such understanding can be stimulated by collaborative modeling activities of the sort made possible by the models presented in this paper. The goals of such modeling are collaborative discovery, creation of multiple explanations, and envisioning alternative futures. Models are co-invented "on the fly" during interactive workshops. The models are collaborative constructs used to evoke collective learning.

Lessons that derive from using these exploratory models include the expectation that dynamics of social-natural systems will have multiple futures, or domains of attraction. Learning about slow variables is revealed to be key to 
sustainability. For some time prior to catastrophic shifts between possible states, the impending collapse is evident to all participants in the modeling exercise, yet they still allow the system to become an accident waiting to happen. Breakdown is inevitable. After collapse, innovation and experimentation are favored. Participants find themselves asking how learning can be stimulated in ways that enhance sustainability. Such modeling exercises create understanding, options in the form of alternative visions of the future, and hope.

There is every reason to have readers of Conservation Ecology part of a network of experimentation using these models. We invite you to do so and to communicate your discoveries using the Response feature. The very diversity of experience and interest of readers can lead to an Internet-facilitated program of collaborative learning. And that experience could help implement development of priorities for the next phase of backloop modeling:

1. Get Real: It is time to connect theory to practice through workshops and individual experiments to codevelop evocative models, intelligent experiments, and collaborative learning in the context of real environmental problem solving for systems currently in the backloop.

2. Compare Heuristics: Use backloop models and new understanding of ways to make decisions that are emerging from animal behavior and cognitive psychology to explore learning methods that provide rich and flexible alternatives to optimality approaches.

3. Explore transformational (panarchic) change through models that help people cope with issues such as land use and co-evolution of social-natural systems.

4. Power up: Expand our applications of backloop models to help people explore the politics of sustainable change.

We hope that the readers of Conservation Ecology will begin to use these models and, by sharing their experience using the Response facility, become part of the first step in a process to achieve these four goals. Let's see what we can co-create!

\title{
RESPONSES TO THIS ARTI CLE
}

Responses to this article are invited. If accepted for publication, your response will be hyperlinked to the article. To submit a comment, follow this link. To read comments already accepted, follow this link.

\author{
Address of Correspondent: \\ C.S. (Buzz) Holling \\ Department of Zoology \\ University of Florida \\ 223 Bartram Hall \\ Gainesville, Florida 32611-2009 USA \\ Phone: (352) 543-6955 \\ Fax: (352) 392-3704 \\ holling@zoo.ufl.edu
}

*The copyright to this article passed from the Ecological Society of America to the Resilience Alliance on 1 January 2000. 
Home | Archives | About | Login | Submissions | Notify | Contact | Search 